\title{
EEG Abnormalities Aid Diagnosis of Rett Syndrome
}

\author{
Elizabeth A. Garofalo, MD*+, Ivo Drury, MD ${ }^{\dagger}$, and Gary W. Goldstein, MD*
}

Nine girls with Rett syndrome had 22 electroencephalographic studies performed over 5 years. Nineteen waking tracings demonstrated moderate background slowing. Focal epileptiform activity was observed in 13 studies, 10 of which had bilateral independent foci. Spikes were invariably maximal in central regions, diphasic or triphasic, and of very short duration. In 3 patients, epileptiform activity preceded clinical seizures by up to 2 years. Two children had spontaneous hyperpnea preceding apnea during wakefulness with further background slowing. Video monitoring of 2 children revealed that episodic behavioral changes were not seizures. Ten of 12 sleep recordings had abnormal background activity with absent or rudimentary spindles. Normal activity occurred only in girls younger than $2 \frac{1}{2}$ years of age. Epileptiform activity was markedly increased during sleep in 8 tracings in which both wakefulness and sleep were obtained. It was characterized by bilaterally independent and bisynchronous spike-and-wave activity, maximal in parasagittal areas. One patient had bursts of high-voltage slow-wave activity followed by attenuation. No apneic episodes were recorded during sleep. In Rett syndrome, electroencephalographic abnormalities include background slowing, centrally located short-duration spikes, and increased epileptiform activity during sleep. This activity commonly preceded clinical seizures in patients studied at initial presentation.

Garofalo EA, Drury I, Goldstein GW. EEG abnormalities aid diagnosis of Rett syndrome. Pediatr Neurol 1988; 4:350-3.

\section{Introduction}

Rett syndrome is a degenerative neurologic condition now recognized only in girls. The clinical features have been well defined [1-3]. Major manifestations include stereotypic hand movements, loss of language and motor skills, and a disordered voluntary respiratory pattern. Because no consistent abnormalities have been found on laboratory studies, Rett syndrome remains a diagnosis of exclusion [4]. Others report a high incidence of age-related electroencephalographic (EEG) changes and seizures $[5,6]$. Further characterization of $22 \mathrm{EEGs}$ in 9 patients revealed typical abnormalities.

\section{Methods}

The population consisted of 9 girls, 10 months to 6 years of age, followed for 6 months to $6 \frac{1}{2}$ years. Seven children developed normally until 12 months of age. One child was hypotonic at birth, then demonstrated appropriate and progressive improvement. One child was 7 weeks premature. All 7 regressed over a number of months with loss of language skills and development of gait ataxia and stereotypic hand movements. Occipitofrontal circumferences disclosed a deceleration in growth after 6 months, commonly before clinical deterioration. Six girls developed irregular respiratory patterns with hyperpnea and apnea; 7 had seizures.

In all patients, cranial computed tomography (CT) scans were normal or revealed mild diffuse atrophy. The following studies were normal or negative in all patients tested (number of patients in parentheses): cranial magnetic resonance imaging (2), urine and blood screening for amino and organic acids (9), cerebrospinal fluid (CSF) (5), lysosomal enzymes (7), karyotypes (4), blood ammonia levels (4), lactate (4), pyruvate (3), venous pH levels (2), buffy-coat electron microscopy (2), sweat gland or skin biopsy (2), evoked potential studies (8), nerve conduction velocities (2), and neopterin/biopterin levels in urine (2). One child (Patient 3) had an elevated CSF biopterin level of $83 \mathrm{pm} / \mathrm{ml}$ (normal: $20-30 \mathrm{pm} / \mathrm{ml}$ ).

Twenty-two EEG studies were obtained with the children ranging in age from 23 months to 9 years. Four patients had 1 recording. The other 5 patients were followed with EEGs for $1-4 \frac{1}{2}$ years. Two had videoEEG studies and 1 had a 24-hour ambulatory cassette recording.

Table 1 summarizes the clinical data from all patients. Two descriptive case reports follow.

Patient 1. This patient was the product of a term, uncomplicated pregnancy, labor, and delivery. Birth weight was $3,870 \mathrm{gm}$. Growth and development during the first year of life were normal. She sat unassisted at 7 months, stood at 12 months, and walked independently at 14 months of age. At that time, she had a vocabulary of 12 words. At 16 months of age, her development reached a plateau. Four months later she experienced a marked regression in mental and motor function over several months. A prominent feature was the loss of meaningful use of her hands. Her gait became ataxic and her stance wide-based. She lost all speech. She did not recognize her family or respond in any meaningful way. This regression stabilized by 26 months of age. At $3 \frac{1}{2}$ years of age, EEG demonstrated bilateral, independent central and temporal spike discharges most prominent during sleep. At age 4 years, she had a series of brief, generalized tonic-ctonic seizures over several days. Carbamazepine was administered and the seizures were controlled.
From the Departments of *Pediatrics and Neurology;

University of Michigan Medical School; Ann Arbor, Michigan.

Presented in part at the Child Neurology Society Meeting,

October, 1987.
Communications should be addressed to:

Dr. Garofalo; Department of Neurology; University of Michigan;

University Hospital 1B300/0036; 1500 East Medical Center Drive:

Ann Arbor, MI 48109-0036.

Received July 8, 1988; accepted August 31, 1988. 
Table 1. Clinical features of Rett syndrome

\begin{tabular}{|c|c|c|c|c|c|c|c|c|c|}
\hline $\begin{array}{l}\text { Patient } \\
\text { Number }\end{array}$ & $\begin{array}{c}\text { Age at Onset } \\
\text { of Stage II } \\
\text { (months) }\end{array}$ & $\begin{array}{c}\text { Length of } \\
\text { Stage II } \\
\text { (months) }\end{array}$ & $\begin{array}{c}\text { Hand } \\
\text { Washing, } \\
\text { Mouthing }\end{array}$ & Apnea & Speech & $\begin{array}{l}\text { OFC/Weight/ } \\
\text { Age (months) }\end{array}$ & Gait & $\begin{array}{l}\text { Leg } \\
\text { Tone }\end{array}$ & $\begin{array}{l}\text { Age at Sei- } \\
\text { zure Onset } \\
\text { (years) }\end{array}$ \\
\hline 1 & 20 & 8 & Present & Present & $\begin{array}{l}8 \text { words } \\
\text { lost }\end{array}$ & $\begin{array}{l}\text { OFC }=50 \% \text { tile/ } \\
\text { Wt }>95 \% \text { tile/ } \\
25 \text { mos }\end{array}$ & Ataxic & Increased & 4 \\
\hline 2 & 20 & 9 & Present & None & $\begin{array}{l}20 \text { words } \\
\text { lost }\end{array}$ & $\begin{array}{l}\text { OFC }<5 \% \text { tile/ } \\
\text { Wt }<5 \% \text { tile/ } \\
30 \text { mos }\end{array}$ & Lost & Increased & $4 \frac{1}{2}$ \\
\hline 3 & 22 & 2 & Present & Present & $\begin{array}{c}\text { Babble } \\
\text { lost }\end{array}$ & $\begin{array}{l}\text { OFC }<5 \% \text { tile/ } \\
\mathrm{Wt}=75 \% \text { tile/ } \\
24 \operatorname{mos}\end{array}$ & Lost & Increased & $2 \frac{1}{2}$ \\
\hline 4 & 24 & 12 & Present & Present & None & $\begin{array}{l}\text { OFC }=5 \% \text { tile } / \\
\mathrm{Wt}=5 \% \text { tile } / \\
36 \text { mos }\end{array}$ & Lost & Increased & 4 \\
\hline 5 & 22 & 6 & Present & Present & $\begin{array}{l}\text { Few words } \\
\text { lost }\end{array}$ & $\begin{array}{l}\text { OFC }<5 \% \text { tile/ } \\
\mathrm{Wt}=10 \% \text { tile/ } \\
22 \mathrm{mos}\end{array}$ & Lost & Increased & 4 \\
\hline 6 & 20 & 2 & Present & None & None & $\begin{array}{l}\text { OFC }<5 \% \text { tile/ } \\
\mathrm{Wt}=25 \% \text { tile } / \\
12 \operatorname{mos}\end{array}$ & None & NA & $21 / 2$ \\
\hline 7 & 24 & 6 & Present & Present & $\begin{array}{l}4 \text { words } \\
\text { lost }\end{array}$ & $\begin{array}{l}\text { OFC }<5 \% \text { tile/ } \\
\text { Wt NA/ } \\
12 \operatorname{mos}\end{array}$ & Ataxic & Normal & None \\
\hline 8 & 18 & 4 & Present & None & $\begin{array}{c}\text { Babble } \\
\text { lost }\end{array}$ & $\begin{array}{l}\text { OFC }=10 \% \text { tile } / \\
\mathrm{Wt}=40 \% \text { tile } / \\
22 \mathrm{mos}\end{array}$ & None & Normal & None \\
\hline 9 & 35 & 12 & Present & Present & $\begin{array}{c}\text { Babble } \\
\text { lost }\end{array}$ & $\begin{array}{l}\mathrm{OFC}=25 \% \text { tile } / \\
\mathrm{Wt}<5 \% \text { tile/ } \\
39 \text { mos }\end{array}$ & None & Increased & $4 \frac{1}{2}$ \\
\hline $\begin{array}{l}\text { Abbrevia } \\
\mathrm{NA}= \\
\mathrm{OFC}=\end{array}$ & $\begin{array}{l}\text { s: } \\
\text { available } \\
\text { ipitofrontal ci }\end{array}$ & mference & & & & & & & \\
\hline
\end{tabular}

On examination at $4 \frac{1}{2}$ years of age she appeared awake and alert. Height and weight were at the 95th percentile, while occipitofrontal circumference was at the 10th percentile. Cranial nerve examination was normal but she had poor, inconsistent eye contact. Motor examination revealed gait ataxia. She had constant hand-washing movements. Muscle tone was normal in the arms and increased in the legs. Muscle stretch reflexes were normal. EEG during sleep demonstrated absence of normal background features and frequent parasagittal spikes (Fig 1).

Patient 2. This patient was born following a pregnancy complicated by hypertension treated with phenobarbital. She was born at term weighing 2,580 gm. Early developmental milestones were normal. She crawled at 12 months of age and began walking at 18 months. At 20 months of age, she had a 15-20 word vocabulary and was able to put 2 words together. She held objects well. By 29 months of age, she had lost her ability to walk, had little purposeful hand use, and often kept her hands in her mouth. Her vocabulary had decreased to 2-3 words. EEG disclosed slow background activity with left centro-temporal spikes. Video-EEG was performed but no clinical seizures were detected. An empiric trial of carbamazepine $200 \mathrm{mg}$ daily was instituted without benefit and was discontinued after several months. At $4 \frac{1}{2}$ years of age, seizures developed which consisted of clonic jerking of the extremities. Seizure control was eventually achieved with the use of phenobarbital and phenytoin. At $7 \frac{1}{2}$ years of age, she was unable to ambulate and had truncal ataxia with a wide-based stance. She had no purposeful use of her hands and no language.

\section{Results}

No EEG was entirely normal. Normal waking background activity was observed in 3 children at 23,25, and 28 months of age. Waking background patterns were slow on presentation in the other 6 patients. Background slowing initially was observed at $2 \frac{1}{2}$ years of age, progressed for 3 years, and then stabilized. Two patients had irregular breathing patterns: hyperpnea alternating with apnea during wakefulness. EEG demonstrated further background slowing but no ictal activity (Fig 2). Sleep recordings of these 2 patients documented no breathing irregularities. At presentation to our institution, 3 patients (all younger than 3 years of age) had no epileptiform activity during wakefulness. In the other 6 patients, waking epileptiform activity 


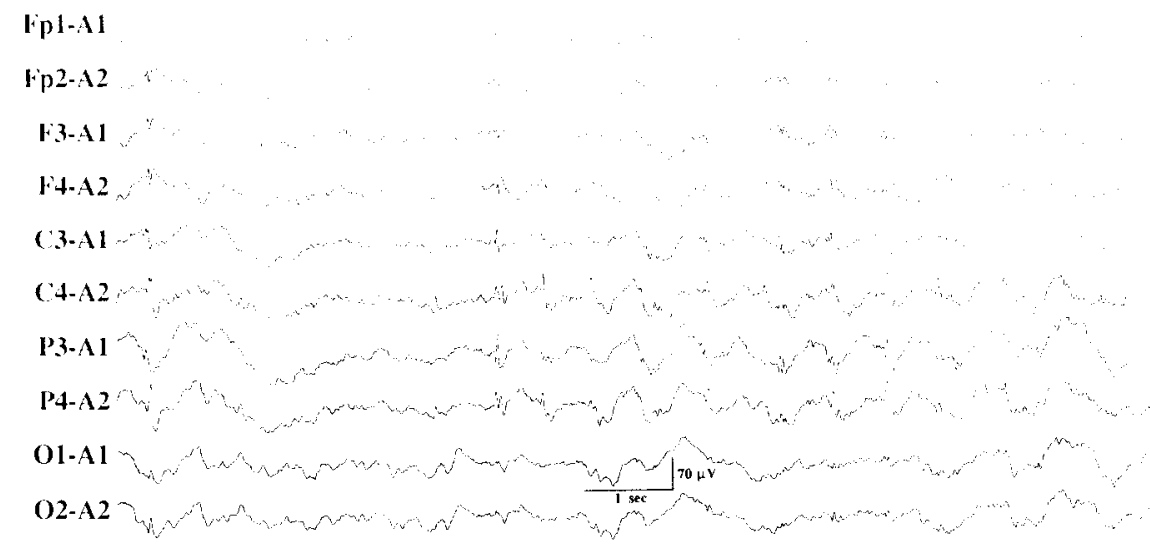

Figure 1. Patient I at $4 \frac{1}{2}$ years of age. EEG recorded during sleep demonstrates absence of normal background features and frequent independent and bisynchronous spikes in parasagittal regions.

was characterized by focal spikes, maximal in parasagittal derivations. The spikes were diphasic or triphasic and of very short duration $(<50 \mathrm{msec}$ ). More generalized activity was present in 1 patient and included $3 \mathrm{~Hz}$ spike-and-wave activity posteriorly.

Sleeping background activity was normal in 3 patients at 21,23 , and 29 months of age. In older children, sleep background was poorly formed or absent. During sleep, epileptiform activity increased markedly with a parasagittal emphasis. Bisynchronous parasagittal activity and generalized polyspike-and-wave discharges were observed in 2 patients, while 1 patient had large-amplitude slow waves followed by periods of attenuation.
The relationship between interictal EEG activities and seizures was variable. At presentation, 3 patients with seizures had epileptiform activity on their initial EEGs, while one patient developed generalized myoclonic seizures without preceding spikes or sharp waves. Three patients with focal epileptiform activity, ages 23-30 months, developed seizures an average of 2 years later. Two patients remain seizure-free, 1 of whom has independent centrotemporal spikes.

Video-EEG monitoring was performed in 2 patients. Episodic behavior, including arm and head movements in one patient and chaotic breathing patterns in the other, was not associated with ictal discharges.

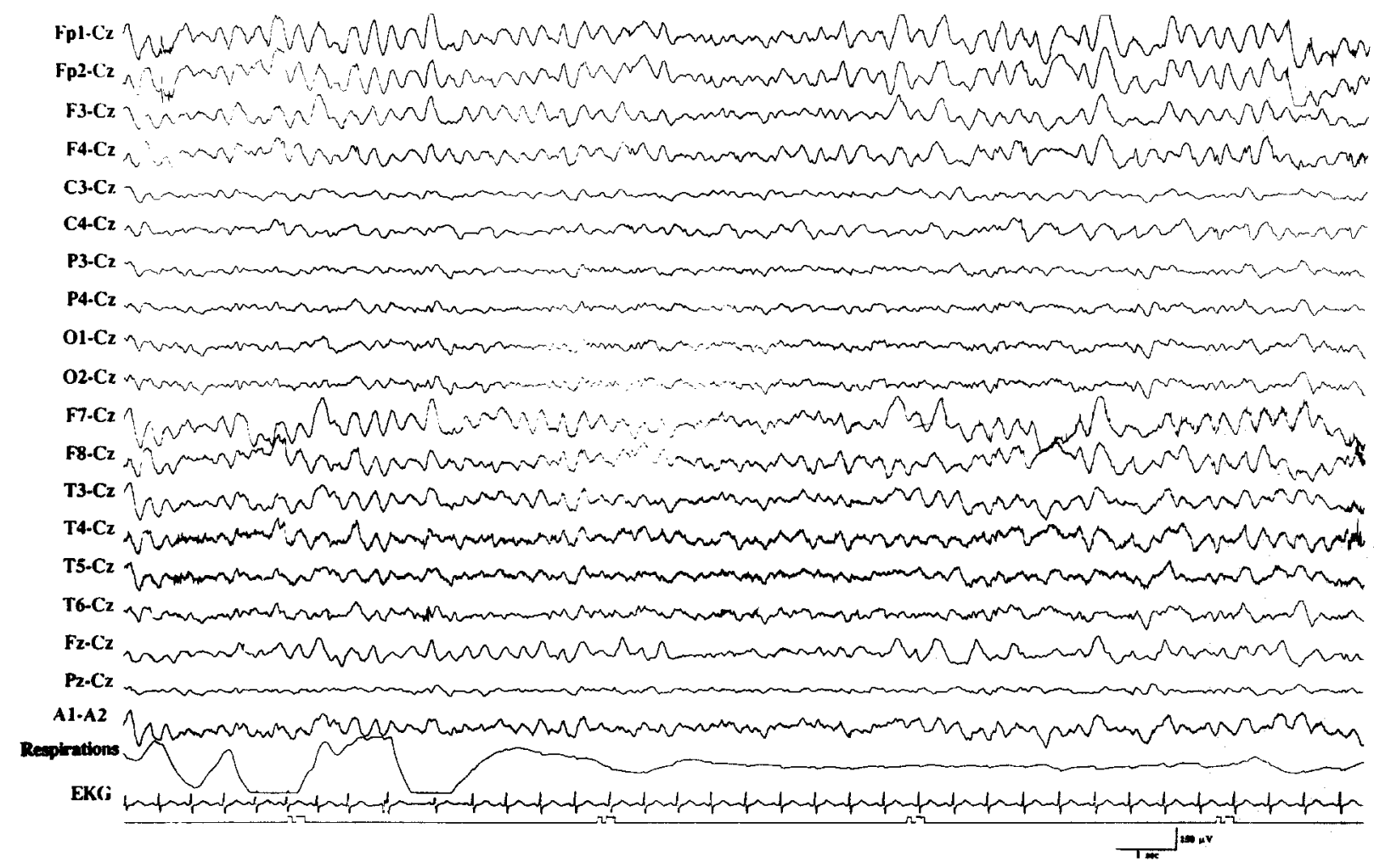

Figure 2. Patient 4 at 10 years of age. Waking EEG with generalized high-amplitude slowing, disorganized breathing, and apneic episode of 28 sec. 


\section{Discussion}

EEGs are commonly obtained in children with developmental regression. In Rett syndrome, which lacks a specific diagnostic test, a number of typical EEG abnormalities are observed. All of our patients presented during or after Stage II, the "rapid destructive phase" of the disease $[3,6]$. In our patients, background slowing often developed during Stage II, as early as 2 years of age, progressed during Stage III (pseudo-stationary stage), up to $5 \frac{1}{2}$ years of age, then stabilized with rhythms in the $4-5 \mathrm{~Hz}$ range. These findings have been described previously by several authors [6-11]; Verma et al. reported the onset of slowing to be later at 5 years of age [5].

While awake, these patients may have very disorganized voluntary breathing patterns [12]. During episodes of hyperventilation and apnea, background activity slows into the delta range. Breathing patterns are consistently normal during sleep [13]. Verma et al. recognized this spontaneous hyperventilation and associated EEG slowing [5], while Haas reported that patients had central apnea during periods of wakefulness [9].

Epileptiform activity is a frequent finding and has a characteristic morphology and location. Seizures develop in $75-80 \%$ of patients. Spikes are diphasic or triphasic and of short duration $(<50 \mathrm{msec})$. They are most prominent in parasagittal derivations. A similar distribution was reported by Robertson et al. [8], while other authors found centroparietal or temporal disturbances $[5,7,9,10]$. Central spikeand-sharp-wave foci are well described in childhood and associated with seizures, spasticity, or poor coordination and mental retardation [14].

Abnormalities of sleep patterns also have been reported by several authors $[7,8,10]$. We found that sleep features were well developed only in patients younger than $2 \frac{1}{2}$ years of age. During the "destructive" phase, mild changes in sleep patterns including decreases or asymmetries in sleep spindles were the first EEG abnormalities observed. In later clinical stages, vertex waves and sleep spindles were poorly formed or absent with more severe abnormalities observed in older children. Epileptiform activity was clearly augmented by sleep in our patients, with a tendency towards more generalized activity in 4 of 9 patients. The effect of sleep stages on background and epileptiform activities is the subject of another presentation [15].

A striking finding in our series was the preserce of prominent epileptiform activity in 3 children early in their clinical courses during the "destructive" phase of the disease. This activity preceded seizures by an average of 2 years. In two children, an empiric trial of antiepileptic drugs was instituted on the basis of the frequent spikes. They demonstrated no sustained improvement over several months and the medication was discontinued. Trauner and Haas suggested that aggressive use of antiepileptic drugs in patients with continuous epileptiform activity during sleep may affect the clinical course of the disease [10]. No comment has been made concerning treatment when this activity precedes seizures. Its relationship to clinical seizure activity and the possibility of early treatment with antiepileptic drugs need further study.

In Rett Syndrome, we found generally consistent EEG abnormalities among patients, including background slowing and centrally located spikes which increased during sleep. Epileptiform activity often preceded the onset of seizures. These typical features along with the lack of a biochemical marker for Rett Syndrome make EEG a useful diagnostic tool.

\section{References}

[1] Naidu S, Murphy M, Moser HW, Rett A. Rett syndromenatural history in 70 cases. Am J Med Genet 1986;24:61-72.

[2] Hagberg B, Goutieres F, Hanefeld F, Rett A, Wilson J. Rett syndrome: Criteria for inclusion and exclusion. Brain Dev 1985;7:372-3.

[3] Rett Syndrome Diagnostic Criteria Work Group. Diagnostic criteria for Rett Syndrome. Ann Neurol 1988;23:425-8.

[4] Nomura Y, Segawa M, Hasegawa M. Rett syndrome - clinical studies and pathophysiological consideration. Brain Dev 1984;6:475-86.

[5] Verma NP, Chheda RL, Nigro MA, Hart ZH. Electroencephalographic findings in Rett syndrome. Electroencephalogr Clin Neurophysiol 1986;64:394-401.

[6] Glaze DG, Frost JD, Zoghbi HY, Percy AK. Rett's syndrome: Correlation of electroencephalographic characteristics with clinical staging. Arch Neurol 1987;44:1053-6.

[7] Niedermeyer E, Rett A, Renner H, Murphy M, Naidu S. Rett syndrome and the electroencephalogram. Am J Med Genet 1986; 24:195-9.

[8] Robertson R, Langill L, Wong PKH. Rett's syndrome: EEG presentation in 6 cases. Electroencephalogr Clin Neurophysiol 1986; 64:79P.

[9] Haas RH, Rice MA, Trauner DA. Therapeutic effects of a ketogenic diet in Rett syndrome. Am J Med Genet 1986;24:225-46.

[10] Trauner DA, Haas RH. Electroencephalographic abnormalities in Rett syndrome. Pediatr Neurol 1987;3:331-4.

[11] Hagberg B, Aicardi J, Dias K, Ramos O. A progressive syndrome of autism, dementia, ataxia, and loss of purposeful hand use in girls: Rett's syndrome: Report of 35 cases. Ann Neurol 1983;14:471-9.

[12] Cirignotta F, Lugaresi E, Montagna P. Breathing impairment in Rett syndrome. Am J Med Genet 1986;24:167-73.

[13] Glaze DG, Frost JD, Zoghbi HY, Percy AK. Rett's syndrome: Characterization of respiratory patterns and sleep. Ann Neurol 1987; 21:377-82.

[14] Smith TM, Kellaway P. Central (rolandic) foci in children: An analysis of 200 cases. Electroencephalogr Clin Neurophysiol 1964; 17:460-1.

[15] Aldrich M, Drury I, Garofalo E. Epileptiform abnormalities during sleep in Rett syndrome. Neurology 1988;38:317. 